J. Lake Sci. (湖泊科学) , 2014, 26(5): 691-697

http://www. jlakes. org. E-mail : jlakes@niglas.ac.cn

(C) 2014 by Journal of Lake Sciences

\title{
$\delta^{13} \mathrm{C}$ 和 $\delta^{15} \mathrm{~N}$ 指示不同生态类型湖泊无机氮及有机质来源”
}

\author{
梁 越 ${ }^{1}$, 肖化云 ${ }^{1,2 * *}$, 刘小真 ${ }^{1 * *}$, 李文华 ${ }^{1}$, 熊 戬 ${ }^{1}$ \\ (1: 南昌大学鄱阳湖环境与资源利用教育部重点实验室, 南昌 330047) \\ (2: 中国科学院地球化学研究所环境地球化学国家重点实验室, 贵阳 550002)
}

摘 要: 为了探讨不同生态类型湖泊 (天然湖泊、城市湖泊) 中无机氮和有机质来源, 分别采集湖泊中水体、表层沉积物、

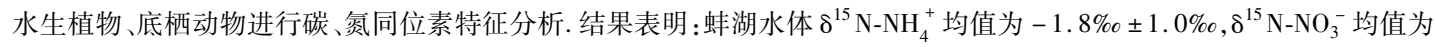

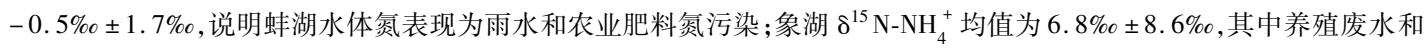
管道排污口 $\delta^{15} \mathrm{~N}^{-\mathrm{NH}_{4}^{+}}$值分别为 $13.5 \%$ 和 $25.4 \%$, 表现出污水氮同位素特征, 象湖 $\delta^{15} \mathrm{~N}^{-\mathrm{NO}_{3}^{-}}$均值为 $-2.9 \% 0 \pm 4.2 \% 0$, 是 氨的硝化作用引起的氮同位素分馏所致. 蚌湖表层沉积物、水生植物 $\delta^{15} \mathrm{~N}$ 差别不大, 分别为 $6.6 \% 0 \pm 0.3 \%$ 、 $7.1 \% 0 \pm 0.7 \% 0$, 水生植物 $\delta^{13} \mathrm{C}$ 均值为 $-27.5 \% 0 \pm 0.3 \%$, 比沉积物 $\delta^{13} \mathrm{C}$ 偏负 $3 \%$. 有机 $\mathrm{C} / \mathrm{N}$ 为 $9.4 \pm 0.5$, 比沉积物 $\mathrm{C} / \mathrm{N}$ 明 显偏高 6 , 反映水生植物是蚌湖有机质的主要来源. 象湖表层沉积物 $\delta^{15} \mathrm{~N} 、 \delta^{13} \mathrm{C}$ 及有机 $\mathrm{C} / \mathrm{N}$ 分布范围大, $\delta^{15} \mathrm{~N}$ 在 $3.6 \% 0 \sim$ $8.3 \%$ 之间, 均值为 $5.9 \% 0 \pm 1.6 \% 0, \delta^{13} \mathrm{C}$ 在 $-27.1 \% 0 \sim-24.7 \%$ 之间, 均值为 $-26.0 \% 0 \pm 1.0 \%$, 有机 $\mathrm{C} / \mathrm{N}$ 在 $2.6 \sim 10.8$ 之 间,均值为 $6.2 \pm 2.7$, 表明城市湖泊沉积有机质来源复杂. 2 个湖泊蛙类 $\delta^{15} \mathrm{~N}$ 组成与各自湖泊表层沉积物 $\delta^{15} \mathrm{~N}$ 组成相 对应.

关键词: $\delta^{13} \mathrm{C} ; \delta^{15} \mathrm{~N}$; 湖泊; 无机氮; 有机质; 来源; 蚌湖; 象湖

\section{Identifying provenance of inorganic nitrogen and organic matter in different ecotype lakes using $\delta^{13} \mathrm{C}$ and $\delta^{15} \mathrm{~N}$}

LIANG Yue ${ }^{1}$, XIAO Huayun ${ }^{1,2}$, LIU Xiaozhen ${ }^{1}$, LI Wenhua ${ }^{1} \&$ XIONG Jian ${ }^{1}$

(1: Key Laboratory of Poyang Lake Environmental and Resource Utilization, Ministry of Education, Nanchang University, Nanchang 330047, P. R. China)

(2: State Key Laboratory of Environmental Geochemistry, Institute of Geochemistry, Chinese Academy of Sciences, Guiyang 550002 , P. R. China)

Abstract: In order to investigate nitrogen provenance in different ecotype lakes (natural or urban), samples of water, surface sediments, hydrophytes and zoobenthos in lakes were collected, and their isotopic compositions of carbon and nitrogen were measured. The results indicated that $\delta^{15} \mathrm{~N}_{-} \mathrm{NH}_{4}^{+}$and $\delta^{15} \mathrm{~N}^{-\mathrm{NO}_{3}^{-}}$in the water of Lake Banghu were $-1.8 \% 0 \pm 1.0 \%$ and $-0.5 \% 0 \pm 1.7 \%$, respectively, which showed the major inorganic nitrogen from rainwater and farming fertilizer. The $\delta^{15} \mathrm{~N}_{-} \mathrm{NH}_{4}^{+}$in Lake Xianghu water was high $(6.8 \% \pm \pm 8.6 \%)$, especially in fish wastewater $(13.5 \% 0)$ and sewage outlet $(25.4 \% 0)$, which showed sewage input. The $\delta^{15} \mathrm{~N}^{-\mathrm{NO}_{3}^{-}}$was partially negative $(-2.9 \% \circ \pm 4.2 \%$ ) and showed that the nitrate nitrogen was not mainly from anthropogenic input. The $\delta^{15} \mathrm{~N}$ of organic matters was not significantly different from that of surface sediments and hydrophyte $(6.6 \% \pm \pm$ $0.3 \%$ and $7.1 \% \circ \pm 0.7 \%$, respectively) in Lake Banghu, so hydrophyte was the major source of organic matter for sediments. In Lake Xianghu, there were wide distributions of $\delta^{15} \mathrm{~N}, \delta^{13} \mathrm{C}$ and organic $\mathrm{C} / \mathrm{N}$ in in the organic matters of sediments $\left(\delta^{15} \mathrm{~N}: 3.6 \% o^{-}\right.$ $8.3 \% o, \delta^{13} \mathrm{C}:-27.1 \% o^{-}-24.7 \%$, organic $\mathrm{C} / \mathrm{N}: 2.6-10.8$, respectively), which implies the complexity of the sources of organic matter provenance in the urban lakes.

* 国家自然科学基金项目 (41263002)、江西省科学技术厅项目 (20123BBG70192) 和江西省教育厅项目 (GJJ13074) 联合资助. 2013-11-12 收稿;2014-01-06 收修改稿. 梁越 (1974 ), 女, 博士, 讲师; E-mail : lyue987465@ sina. com.

** 通信作者;E-mail:xiaohuayun@ vip. skleg. cn; liuxiaozhen@ ncu. edu. cn. 
Keywords: $\delta^{13} \mathrm{C} ; \delta^{15} \mathrm{~N}$; lake; inorganic nitrogen; organic matter; provenance; Lake Banghu; Lake Xianghu

水体过量的 N、P 营养盐将导致水域富营养化 ${ }^{[1]}$, 研究表明亚洲 $54 \%$ 、欧洲 $53 \%$ 、北美洲 $48 \%$ 、南美洲 $41 \%$ 、非洲 $28 \%$ 的湖泊水库发生了富营养化, 富营养化成为最严重的环境问题之一 ${ }^{[2]}$. 城市湖泊大多是浅水 封闭型湖泊,水流缓慢、水体交换能力差、营养盐输人来源广泛. 随着城市进程的加快, 越来越多的生活污水 被排人城市湖泊中, 导致湖泊水质普遍低于《地面水环境质量标准》( GB/T 3838-1988) V 类标准, 达到富 营养化甚至极富营养化的水平 ${ }^{[3]} . \delta^{15} \mathrm{~N}$ 技术示踪含氮物质的来源、污染途径、迁移转化方式等, 在国内外已 得到广泛应用 ${ }^{[4.5]}$. 湖泊水体营养盐输入特征, 结合水体、沉积物 $\delta^{13} \mathrm{C} 、 \delta^{15} \mathrm{~N}$ 及有机 $\mathrm{C} / \mathrm{N}$ 可以更好地反映湖泊 富营养化以及有机质的物源、特性、降解程度等生物地球化学问题 ${ }^{[6]}$.

本文选择城市湖泊——南昌市象湖和天然湖泊——鄱阳湖区蚌湖 2 个不同类型的湖泊作为研究对 象, 从水体氮含量、表层沉积物有机碳氮含量、水质参数等多方面人手, 结合湖泊水体、表层沉积物、底栖 动物、水生植物碳氮稳定同位素特征, 对比探讨 2 个不同类型湖泊氮污染来源, 有利于湖泊环境保护与 治理.

\section{1 材料与方法}

\section{1 样品采集与处理}

蛙湖位于江西省星子县南部, 属于中国第一大淡水湖——鄱阳湖边缘的天然湖泊, 面积 $80 \mathrm{~km}^{2}$. 由于鄱阳 湖高变幅水位 (洪水一片, 枯水一线), 蚌湖在秋、冬季湖水退落, 通过天然堤坝与鄱阳湖分离形成独立湖泊, 仅 在东北角上有一窄出湖口, 随着水量的蒸发和流出, 蚌湖自身也被分割成几个小湖泊, 水深只有 $0.5 \sim 1.0 \mathrm{~m}$, 退水后的湿地植被则大量萌发形成草洲. 象湖位于南昌市城南, 属于典型的城市湖泊, 面积 $2.4 \mathrm{~km}^{2}$, 平均水 深4 $\mathrm{m}$, 象湖在南昌市起着蓄水、泄洪、景观作用.

本研究于 2011 年 10 月分别在蚌湖和象湖同时采集水样、表层沉积物和河蛙 (选取同样大小的三角帆 蚌, Hyriopsis cumingii) 样品, 蚌湖还采集了大型水生浮叶植物 (荇菜) 样品, 象湖未见大型水生植物. 研究区 域及采样点见图 1,其中象湖采样点 e1 和 e7 分别是鱼塘养殖废水和管道排污口.

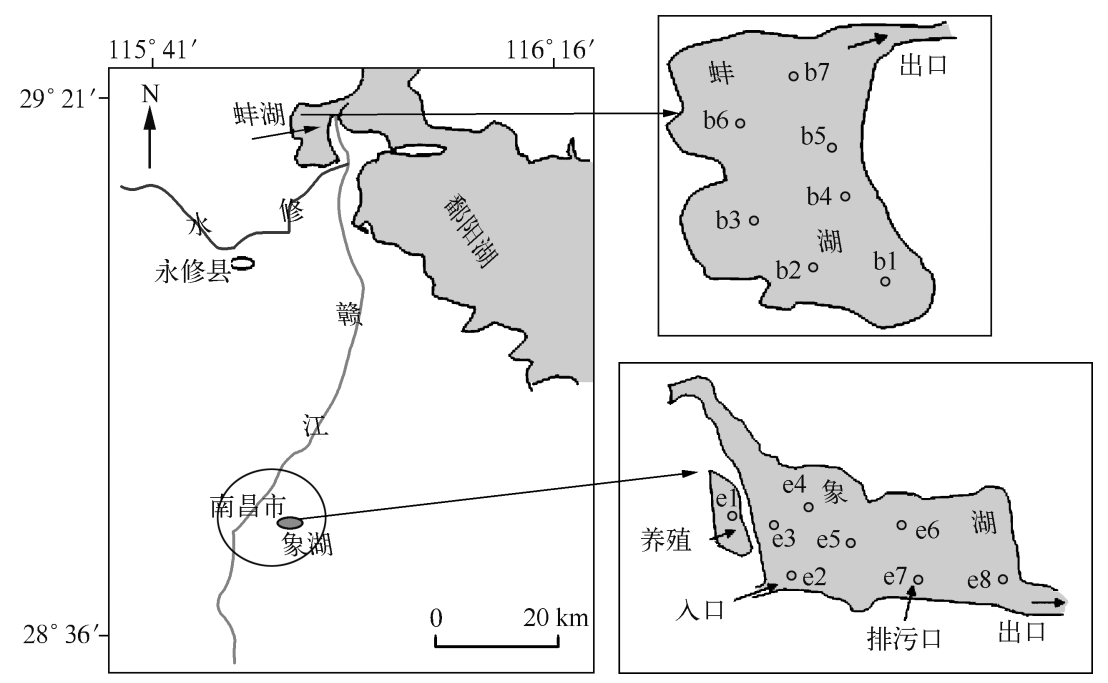

图 1 研究区域及象湖和蚌湖采样点示意

Fig. 1 Schematic of study area and sampling sites in Lake Banghu and Lake Xianghu

采样时采用 GPS 定位, 水样用 $5 \mathrm{~L}$ 有机玻璃采水器采集湖水表层 $0.5 \mathrm{~m}$ 处的水样, 密封保存于干净聚乙 烯塑料瓶中, 用于水体理化指标和氮同位素分析. 表层沉积物样品利用内径 $10 \mathrm{~cm}$ 、厚度 $5 \mathrm{~cm}$ 的自制聚丙烯 
筒式采样器采集 $0 \sim 5 \mathrm{~cm}$ 的沉积物, 3 次采样合并为 1 个样品, 存放于聚乙烯自封袋中, 弃除上层湖水后密 封. 所采样品 $4 \mathrm{~h}$ 内送实验室 $4^{\circ} \mathrm{C}$ 保存 (植物样品经数次纯水洗涤, 河蚌取肌肉部分), 并尽快进行水质和同 位素分析.

\section{2 水体理化指标和同位素分析}

水体理化指标总氮 $(\mathrm{TN})$ 、总磷 $(\mathrm{TP})$ 、铵态氮 $\left(\mathrm{NH}_{4}^{+}-\mathrm{N}\right)$ 、硝态氮 $\left(\mathrm{NO}_{3}^{-}-\mathrm{N}\right) 、 \mathrm{HCO}_{3}^{-}$(不酸化) 和重铬酸盐 指数 $\left(\mathrm{COD}_{\mathrm{Cr}_{\mathrm{r}}}\right)$ 浓度, 分别采用过硫酸钾氧化紫外分光光度法、过硫酸钾氧化锄锑抗分光光度法、纳氏试剂光 度法、酚二磺酸光度法、酸碱指示剂滴定法和重铬酸钾氧化滴定法进行测定, 具体方法参考《水和废水监测 分析方法 $\rangle^{[7]}$.

固体样品:冷冻干燥后用玛瑙研针研磨成粉末并过 100 目篮.

表层沉积物样品总有机碳 (TOC) 前处理: 取 $2 \mathrm{~g}$ 混匀泥样加人 $5 \%$ 的 $\mathrm{HCl}$, 振荡 $1 \mathrm{~h}$, 静置 $24 \mathrm{~h}, 3000$ 转/ $\min$ 离心 $25 \mathrm{~min}$,去除上清液后以超纯水洗涤数次至中性,冷冻干燥后研磨成粉末.

表层沉积物样品 TOC、TN、C/N 以及植物和河蛙 TN、C/N 的分析 : 取适量样品于元素分析仪 (VarioMacro, German) 中进行测定.

水样 $\mathrm{NO}_{3}^{-}-\mathrm{N} 、 \mathrm{NH}_{4}^{+}-\mathrm{N}$ 氮同位素分析: 在表层 $0.5 \mathrm{~m}$ 深度处采集水样 $1.25 \mathrm{~L}$, 于 $0.7 \mu \mathrm{m}$ Millpore 玻 璃纤维滤膜 (预先在 $450^{\circ} \mathrm{C}$ 马弗炉烧 $2 \mathrm{~h}$ 以上) 过滤, 并存放于 $0 \sim 4^{\circ} \mathrm{C}$ 冰箱, 水样 $\mathrm{NO}_{3}^{-} 、 \mathrm{NH}_{4}^{+}$富集后分 别过阴阳离子交换树脂 Dowex1-x8、Dowex50w-x8, 并用 $2 \mathrm{~mol} / \mathrm{L} \mathrm{KCl}$ 洗脱, 再扩散 $10 \sim 15 \mathrm{~d}, \mathrm{NO}_{3}^{-}$的洗 脱液中还要加人定氮合金 ${ }^{[8]}$, 最后冷冻干燥, 取适量于锡杯压实在连续流同位素质谱仪 (CF-IRMS, Euro3000, Isoprine) 上分析 $\delta^{15} \mathrm{~N}$ 值, 以标定硫酸铵和 IAEA 硫酸铵分别为工作标准和国际标准, 分析误 差为 $\pm 0.3 \%$.

表层沉积物、植物和河蚌的 $\delta^{15} \mathrm{~N}$ 分析: 分别取适量预处理好的样品于石英管 (预先在马弗炉 $850^{\circ} \mathrm{C}$ 灼烧 $2 \mathrm{~h}$ ) 中, 并加人 $2 \sim 3 \mathrm{~g} \mathrm{CuO}$ 丝、1 2 $\mathrm{g}$ 线状精 $\mathrm{Cu}$ 丝, 在真空系统中抽高真空后焊封, 于马弗炉 $850^{\circ} \mathrm{C}$ 灼烧 $5 \mathrm{~h}$, 而后在 Finnigan MAT252 同位素质谱仪上纯化 $\mathrm{N}_{2}$ 并测定 $\delta^{15} \mathrm{~N}$ 值, 以大气 $\mathrm{N}_{2}$ 和 IAEA 硝酸钾为参比气和 国际标准,分析误差为 $\pm 0.2 \%$.

表层沉积物 (TOC)、植物和河蚌 $\delta^{13} \mathrm{C}$ 分析 : 分别取适量预处理好的样品于石英管 (预先在马弗炉 $850^{\circ} \mathrm{C}$ 灼烧 $2 \mathrm{~h}$ ) 中,加人 $2 \sim 3 \mathrm{~g} \mathrm{CuO}$ 丝, 在真空系统中抽高真空后焊封,于马弗炉 $850^{\circ} \mathrm{C}$ 灼烧 $5 \mathrm{~h}$, 而后在真空系统 中纯化 $\mathrm{CO}_{2}$, 并在 Finnigan MAT252 同位素质谱仪上测定 $\delta^{13} \mathrm{C}$ 值, 以美国南卡罗莱纳州白严系 Pee Dee 组拟 箭石化石 (简称 PDB) 作为标准品, 分析误差为 $\pm 0.2 \%$.

$\delta^{15} \mathrm{~N}\left(\right.$ 或 $\left.\delta^{13} \mathrm{C}\right)=1000\left(R_{\text {样品 }} / R_{\text {标准 }}-1\right)$, 式中, $R$ 为 ${ }^{15} \mathrm{~N} /{ }^{14} \mathrm{~N}\left(\right.$ 或 $\left.{ }^{13} \mathrm{C} /{ }^{12} \mathrm{C}\right)$ 自然丰度比.

运用 SPSS 19.0 和 Sigmaplot 10.0 软件进行数据统计分析和作图.

\section{2 结果与讨论}

\section{1 水体理化指标特征}

蛙湖的水体 $\mathrm{pH}$ 值在 $7.37 \sim 8.29$ 之间, 均值为 $7.64 \pm 0.39$, 湖水偏弱碱性 (表 1 ), 这可能受蚌湖地质土 壤环境影响. 象湖的水体 $\mathrm{pH}$ 值在 $5.80 \sim 6.50$ 之间,均值为 $6.14 \pm 0.23$, 象湖水源主要来自城市地下管网排 水及周边地区降雨来水. 1990s 以来, 以南昌、长沙等中、东部城市为中心的酸雨区污染水平超过了西南酸雨 区, 成为全国酸雨污染最严重的区域 ${ }^{[9-10]}$, 象湖水质偏酸性,可能与降雨有关, 在酸性条件下物质更容易发生 物理化学反应,有利于底泥中污染物释放.

$\mathrm{COD}_{\mathrm{Cr}}$ 是有机物污染指标,象湖水体的 $\mathrm{COD}_{\mathrm{Cr}}$ 含量偏高, 尤其是鱼养殖废水 $\mathrm{e}$ 和管道排污口 $\mathrm{e} 7$ 的 $\mathrm{COD}_{\mathrm{Cr}}$ 含量较高, 分别为 54.998 和 $155.040 \mathrm{mg} / \mathrm{L}$, 表明象湖人为有机物污染较严重.

湖水中的 $\mathrm{HCO}_{3}^{-}$主要来源于大气中 $\mathrm{CO}_{2}$ 的溶解、湖泊中有机质的氧化和流域土壤中的 $\mathrm{HCO}_{3}^{-}$. 蚌湖 $\mathrm{HCO}_{3}^{-}$含量在 $48.35 \sim 70.00 \mathrm{mg} / \mathrm{L}$ 之间, 均值为 $64.00 \pm 14.59 \mathrm{mg} / \mathrm{L}$, 其中 b7 (出湖口) $\mathrm{HCO}_{3}^{-}$含量为 90.25 $\mathrm{mg} / \mathrm{L}$, 远低于象湖 $\mathrm{HCO}_{3}^{-}$均值 $(112.89 \pm 54.12 \mathrm{mg} / \mathrm{L})$, 而 $\mathrm{el} 、 \mathrm{e} 7$ 采样点 $\mathrm{HCO}_{3}^{-}$含量分别为 $179.20 、 209.50$ $\mathrm{mg} / \mathrm{L}$. 
表 1 蚌湖和象湖水体理化参数

Tab. 1 Physical and chemical parameters of water body in Lake Banghu and Lake Xianghu

\begin{tabular}{ccccccccc}
\hline \multirow{2}{*}{ 湖泊 } & 统计量 & $\mathrm{pH}$ & $\begin{array}{r}\mathrm{HCO}_{3}^{-} / \\
(\mathrm{mg} / \mathrm{L})\end{array}$ & $\begin{array}{r}\mathrm{COD}_{\mathrm{Gr}} / \\
(\mathrm{mg} / \mathrm{L})\end{array}$ & $\begin{array}{r}\mathrm{NH}_{4}^{+}-\mathrm{N} / \\
(\mathrm{mg} / \mathrm{L})\end{array}$ & $\begin{array}{r}\mathrm{NO}_{3}^{-}-\mathrm{N} / \\
(\mathrm{mg} / \mathrm{L})\end{array}$ & $\begin{array}{r}\mathrm{TN} / \\
(\mathrm{mg} / \mathrm{L})\end{array}$ & $\begin{array}{c}\mathrm{TP} / \\
(\mathrm{mg} / \mathrm{L})\end{array}$ \\
\hline \multirow{2}{*}{ 蚌湖 } & 平均值 & 7.6 & 64.00 & 15.63 & 0.33 & 0.10 & 1.77 & 0.10 \\
& 标准偏差 & 0.4 & 14.59 & 4.59 & 0.04 & 0.06 & 1.13 & 0.03 \\
& 最大值 & 8.3 & 90.25 & 22.20 & 0.37 & 0.22 & 3.51 & 0.14 \\
& 最小值 & 7.3 & 48.35 & 8.81 & 0.27 & 0.06 & 1.04 & 0.06 \\
\multirow{6}{*}{ 象湖 } & 平均值 & 6.1 & 112.89 & 43.67 & 4.34 & 0.75 & 11.32 & 0.62 \\
& 标准偏差 & 0.2 & 54.12 & 46.92 & 1.99 & 0.37 & 4.54 & 0.98 \\
& 最大值 & 6.5 & 209.50 & 155.04 & 9.12 & 1.24 & 20.69 & 3.05 \\
& 最小值 & 5.8 & 64.46 & 13.06 & 2.94 & 0.37 & 7.11 & 0.19 \\
\hline
\end{tabular}

氮在水体中存在的形式主要有 $\mathrm{NH}_{4}^{+}-\mathrm{N} 、 \mathrm{NO}_{3}^{-}-\mathrm{N}$ 、有机氮. $\mathrm{NH}_{4}^{+}-\mathrm{N}$ 是蚌湖和象湖的主要无机氮形式, 蚌湖 $\mathrm{NH}_{4}^{+}-\mathrm{N}$ 含量为 $0.33 \pm 0.04 \mathrm{mg} / \mathrm{L}$; 象湖的 $\mathrm{NH}_{4}^{+}-\mathrm{N}$ 含量较高, 范围在 $2.94 \sim 9.12 \mathrm{mg} / \mathrm{L}$ 之间 (表 1), 均值为 $4.34 \pm 1.99 \mathrm{mg} / \mathrm{L}$, 为蚌湖 $\mathrm{NH}_{4}^{+}-\mathrm{N}$ 的 10 多倍, 其中 e1 为 $4.29 \mathrm{mg} / \mathrm{L}, \mathrm{e} 7$ 为 $9.12 \mathrm{mg} / \mathrm{L}$. 象湖 $\mathrm{NH}_{4}^{+}-\mathrm{N}$ 含量主 要受生活污水和地表雨水径流的影响, 排人湖泊的生活污水含有高浓度的 $\mathrm{NH}_{4}^{+}-\mathrm{N}$.

湖水 $\mathrm{NO}_{3}^{-}-\mathrm{N}$ 来源于雨水、工农业活动、交通工具排放、湖泊内源 $\mathrm{NH}_{4}^{+}-\mathrm{N}$ 的硝化作用. 蚌湖 $\mathrm{NO}_{3}^{-}-\mathrm{N}$ 含量 在 $0.06 \sim 0.22 \mathrm{mg} / \mathrm{L}$ 之间, 均值为 $0.10 \pm 0.06 \mathrm{mg} / \mathrm{L}, \mathrm{b} 7$ (出湖口) $\mathrm{NO}_{3}^{-}-\mathrm{N}$ 含量稍高, 为 $0.22 \mathrm{mg} / \mathrm{L}$. 象湖 $\mathrm{NO}_{3}^{-}-\mathrm{N}$ 含量在 $0.37 \sim 1.24 \mathrm{mg} / \mathrm{L}$ 之间, 均值为 $0.75 \pm 0.37 \mathrm{mg} / \mathrm{L}, \mathrm{e} 1 、 \mathrm{e} 7$ 采样点 $\mathrm{NO}_{3}^{-}-\mathrm{N}$ 含量相对较低, 分别 为 $0.47 、 0.37 \mathrm{mg} / \mathrm{L}$, 相反 $\mathrm{NH}_{4}^{+}-\mathrm{N}$ 含量在这 2 个采样点最高, 这可能是污水中溶解氧低、硝化作用弱、 $\mathrm{NH}_{4}^{+}$尚 未氧化成 $\mathrm{NO}_{3}^{-}$或是有机质氧化消耗了废水中的 $\mathrm{NO}_{3}^{-}$. Quirós ${ }^{[11]}$ 研究 400 多个湖泊的 $\mathrm{NH}_{4}^{+}-\mathrm{N} 、 \mathrm{NO}_{3}^{-}-\mathrm{N}$ 含量 发现, $\mathrm{NH}_{4}^{+}-\mathrm{N}$ 含量在超富营养化湖泊中急剧上升,而 $\mathrm{NO}_{3}^{-}-\mathrm{N}$ 含量上升不明显.

\section{2 同位素分析}

2.2.1 水体氮同位素 不同来源、不同形态的氮具有不同的氮稳定同位素值, 比如合成化肥 $\delta^{15} \mathrm{~N}$ 在 $0 \%$ 左 右, 土壤有机氮 $\delta^{15} \mathrm{~N}$ 在 2\%o 8\%o之间, 动物排泄物 $\delta^{15} \mathrm{~N}$ 在 8\%o 20\%o之间, 雨水 $\delta^{15} \mathrm{~N}^{-\mathrm{NH}_{4}^{+}}$在 $-30 \% 0 \sim 0 \%$ 之 间, 雨水 $\delta^{15} \mathrm{~N}-\mathrm{NO}_{3}^{-}$在 $-10 \% 0 \sim 2 \%$ 之间, 因此氮同位素比值 $\left({ }^{15} \mathrm{~N} /{ }^{14} \mathrm{~N}\right)$ 被广泛应用于水体中氮源的示踪 ${ }^{[12-13]}$.

象湖和蚌湖水体 $\mathrm{NH}_{4}^{+}-\mathrm{N} 、 \mathrm{NO}_{3}^{-}-\mathrm{N}$ 浓度和 $\delta^{15} \mathrm{~N}^{-\mathrm{NH}_{4}^{+}}$分布有较大差异 $\left(t\right.$ 检验, 两湖泊 $P_{\mathrm{NH}^{+}-\mathrm{N}}=0.001$ 、 $P_{\mathrm{NO}_{3}^{-\mathrm{N}}}=0.001 、 P_{\delta^{i s} \mathrm{NNH}_{4}^{+}}=0.026$, 差异显著), 而象湖和蚌湖 $\delta^{15}{\mathrm{~N}-\mathrm{NO}_{3}^{-}}^{-}$异不显著 $\left(P_{\delta^{\mathrm{s}} \mathrm{N}-\mathrm{NO} 0_{3}^{-}}=0.204\right)$ (图 2). 蚌湖 $\mathrm{NH}_{4}^{+}-\mathrm{N}$ 含量和 $\delta^{15} \mathrm{~N}^{-\mathrm{NH}_{4}^{+}}$值都较集中, $\delta^{15} \mathrm{~N}^{-\mathrm{NH}_{4}^{+}}$在 $-3.5 \%$ 0.6\% 之间, 均值为 $-1.8 \% 0 \pm 1.0 \%$; $\mathrm{NO}_{3}^{-}-\mathrm{N}$ 含量和 $\delta^{15} \mathrm{~N}^{-N^{-}} \mathrm{N}_{3}^{-}$都偏低, $\delta^{15} \mathrm{~N}^{-\mathrm{NO}_{3}^{-}}$均值为 $-0.5 \% 0 \pm 1.7 \%$, 蚌湖水体 $\delta^{15} \mathrm{~N}$ 特征表现为雨水和农业 肥料氮污染来源. 象湖 $\mathrm{NH}_{4}^{+}-\mathrm{N}$ 含量高, $\delta^{15} \mathrm{~N}^{-\mathrm{NH}_{4}^{+}}$范围在 $0.4 \% 0 \sim 25.4 \%$ 之间, 均值为 $6.8 \% 0 \pm 8.6 \%$, 污染点 e1 和 e7 $\delta^{15} \mathrm{~N}^{-\mathrm{NH}_{4}^{+}}$值分别为 $13.5 \%$ 和 $25.4 \%$, 表现出废水源氮同位素特征 ${ }^{[14-15]}$, 反映出 e1 和 e7 污染点主 要是废水源. 象湖 $\mathrm{NO}_{3}^{-}-\mathrm{N}$ 含量相对 $\mathrm{NH}_{4}^{+}-\mathrm{N}$ 含量低很多, 但相对蚌湖 $\mathrm{NO}_{3}^{-}-\mathrm{N}$ 含量偏高, 而其 $\delta^{15} \mathrm{~N}^{-\mathrm{NO}_{3}^{-}}$在 $-9.2 \% 0 \sim 1.3 \%$ 之间, 均值为 $-2.9 \% 0 \pm 4.2 \%$, 偏负 (有 2 个采样点为 $-8.2 \%$ 和 $-9.2 \%$ ). 象湖 $\mathrm{NH}_{4}^{+}-\mathrm{N}$ 主 要表现为污水输人, $\mathrm{NO}_{3}^{-}-\mathrm{N}$ 并不主要来源于人为输人, 还与湖泊本身发生的生物地球化学行为有关, 因为象 湖溶解氧较低, 硝化作用较弱并且在硝化作用过程中伴随着明显的氮同位素分馏, 产生的 $\mathrm{NO}_{3}^{-}$氮同位素明 显偏负.

2.2.2 沉积物有机质碳、氮同位素沉积物 $\delta^{13} \mathrm{C} 、 \delta^{15} \mathrm{~N}$ 及有机 $\mathrm{C} / \mathrm{N}$ 与有机质来源有关, 在水环境中, 有机 质的 $\delta^{13} \mathrm{C} 、 \delta^{15} \mathrm{~N}$ 结合有机 $\mathrm{C} / \mathrm{N}$ 可以有效地示踪有机质的来源 ${ }^{[16-17]}$, 通常陆源有机质 $\delta^{13} \mathrm{C} 、 \delta^{15} \mathrm{~N}\left(\delta^{13} \mathrm{C}\right.$ : $-28 \% 0 \sim-25 \%$, $\left.\delta^{15} \mathrm{~N}: 0.2 \% 0 \sim 4 \% o\right)$ 与海源有机质 $\delta^{13} \mathrm{C} 、 \delta^{15} \mathrm{~N}\left(\delta^{13} \mathrm{C}:-23 \% o \sim-18 \% o, \delta^{15} \mathrm{~N}: 4 \% o \sim 10 \% 0\right)$ 有显 著不同, 废水污物 $\delta^{13} \mathrm{C} 、 \delta^{15} \mathrm{~N}\left(\delta^{13} \mathrm{C}:-27 \% 0 \sim-25 \% 0, \delta^{15} \mathrm{~N}: 1.4 \% o \sim 3.3 \% 0\right)$ 与陆源有机质 $\delta^{13} \mathrm{C} 、 \delta^{15} \mathrm{~N}$ 通常有 

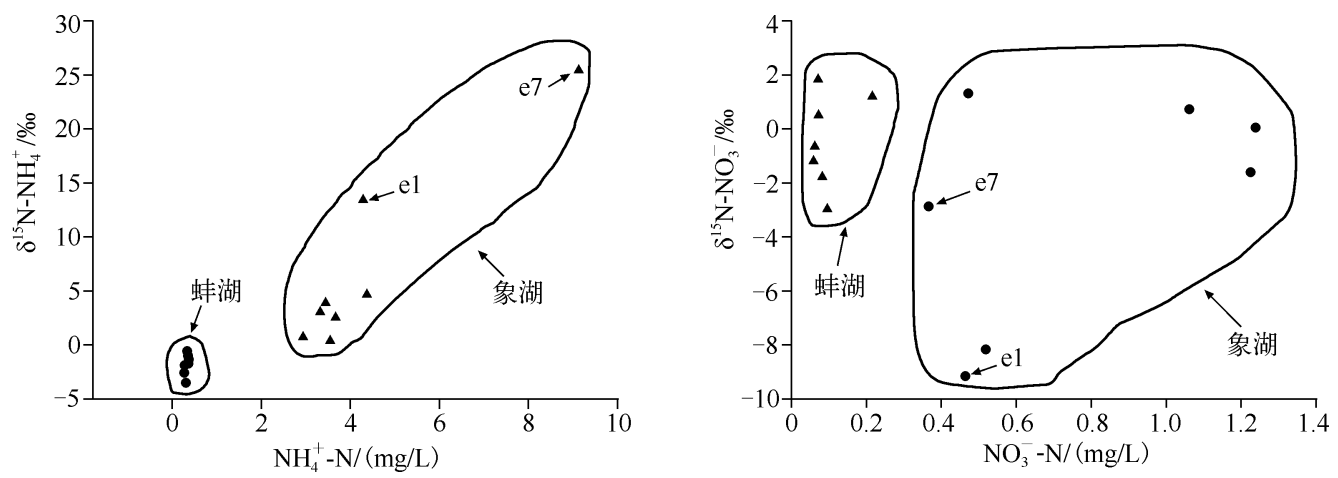

图 2 象湖和蚌湖水体 $\mathrm{NH}_{4}^{+}-\mathrm{N} 、 \mathrm{NO}_{3}^{-}-\mathrm{N}$ 含量及其 $\delta^{15} \mathrm{~N}$

Fig. 2 Contents of $\mathrm{NH}_{4}^{+}-\mathrm{N}, \mathrm{NO}_{3}^{-}-\mathrm{N}$ and its $\delta^{15} \mathrm{~N}$ in water body of Lake Banghu and Lake Xianghu

重叠, 不好区分. 陆源 $\mathrm{C} 3 、 \mathrm{C} 4$ 植物结合 $\mathrm{C} / \mathrm{N}$ 可以有效区分水生植物, 水生生物的降解产物含有较多的蛋白 质,其有机 $\mathrm{C} / \mathrm{N}$ 一般小于 7 , 而陆源植物富含木质素而蛋白质较少, 有机 $\mathrm{C} / \mathrm{N}$ 值通常为 $20 \sim 30$, 同时有机质 的降解也将改变 $\mathrm{C} / \mathrm{N}^{[18-19]}$.

蚌湖是天然湖泊, 受人为污染较少. 蚌湖表层沉积物 $\delta^{15} \mathrm{~N}(\mathrm{TN})$ 均值为 $6.6 \% 0 \pm 0.3 \%$; 有机 $\delta^{13} \mathrm{C}(\mathrm{TOC})$ 在 $-25.1 \% 0 \sim-23.8 \%$ 之间, 均值为 $-24.4 \% 0 \pm 0.4 \%$; 有机 $\mathrm{C} / \mathrm{N}$ 在 $2.7 \sim 3.3$ 之间, 均值为 $2.9 \pm 0.2$ (图 3 ). 蚌湖大型水生浮叶植物 $\delta^{15} \mathrm{~N}$ 为 $7.1 \% 0 \pm 0.7 \%$, 与沉积物相近 (浮叶植物偏高 $0.5 \% 0$ ), 蚌湖水草丰富, 表 明蚌湖沉积物 $\delta^{15} \mathrm{~N}$ 组成主要受水生植物 $\delta^{15} \mathrm{~N}$ 的影响. 水生植物 $\delta^{13} \mathrm{C}$ 均值为 $-27.5 \% 0 \pm 0.3 \%$, 比沉积物
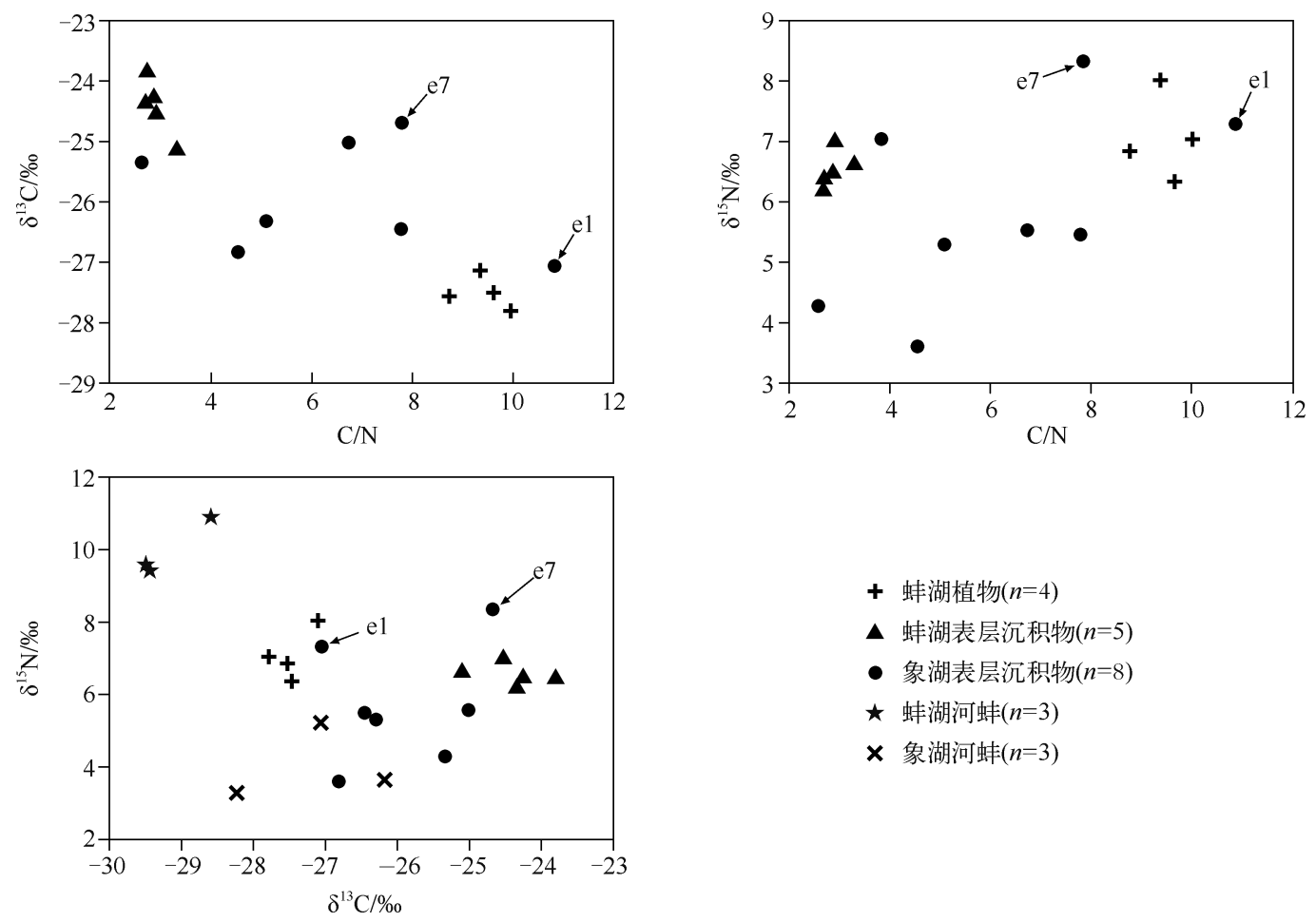

+ 蛙湖植物 $(n=4)$

\ 蚌湖表层沉积物 $(n=5)$

- 象湖表层沉积物 $(n=8)$

$\star$ 蚌湖河蚌 $(n=3)$

$\times$ 象湖河蚝 $(n=3)$

图 3 蚌湖和象湖表层沉积物、水生植物、河蛙的 $\delta^{13} \mathrm{C} 、 \delta^{15} \mathrm{~N}$ 及有机 $\mathrm{C} / \mathrm{N}$

Fig. $3 \delta^{13} \mathrm{C}, \delta^{15} \mathrm{~N}$ and organic $\mathrm{C} / \mathrm{N}$ of surface sediment, hydrophyte and calm in the Lake Banghu and Lake Xianghu 
$\delta^{13} \mathrm{C}$ 偏负 $3 \%$. 水生植物有机 $\mathrm{C} / \mathrm{N}$ 为 $9.4 \pm 0.5$, 比沉积物 $\mathrm{C} / \mathrm{N}$ 明显偏高 6 , 这是沉积物有机质在形成过程中 不断被微生物降解, $\mathrm{C}$ 元素以 $\mathrm{CO}_{2}$ 形式逸出, 而 $\mathrm{N}$ 元素被微生物固定的结果 ${ }^{[6]}$, 因而沉积物有机质含 $\mathrm{N}$ 量比 水生植物高, 有机 $\mathrm{C} / \mathrm{N}$ 低. 因此, 研究表明蚌湖内源水生生物是沉积有机质的主要来源.

象湖是城市湖泊, 受人为干扰大. 象湖表层沉积物 $\delta^{15} \mathrm{~N} 、 \delta^{13} \mathrm{C}$ 及有机 $\mathrm{C} / \mathrm{N}$ 变化范围都比蚌湖大, 其 $\delta^{15} \mathrm{~N} 、 \delta^{13} \mathrm{C}$ 比蚌湖偏低偏负,有机 $\mathrm{C} / \mathrm{N}$ 比蚌湖高(图 3). $\delta^{15} \mathrm{~N}$ 在 3.6\%o 8.3\%o 之间,均值为 $5.9 \% 0 \pm 1.6 \%$; $\delta^{13} \mathrm{C}$ 在 $-27.1 \% 0 \sim-24.7 \%$ 之间,均值为 $-26.0 \% 0 \pm 1.0 \%$; 有机 $\mathrm{C} / \mathrm{N}$ 在 $2.6 \sim 10.8$ 之间, 均值为 $6.2 \pm 2.7$. 其中 $\mathrm{e} 1 、 \mathrm{e} 7$ 的 $\delta^{15} \mathrm{~N} 、 \delta^{13} \mathrm{C}$ 、有机 $\mathrm{C} / \mathrm{N}$ 都比其它采样点高, $\delta^{15} \mathrm{~N}$ 分别为 $7.3 \%$ 、 $8.3 \%$, $\delta^{13} \mathrm{C}$ 分别为 $-27.1 \%$ 、 $-24.7 \%$, 有机 $\mathrm{C} / \mathrm{N}>8$, 这与贵阳市南明河排污口研究结果相似 ${ }^{[16]}$, 表现为废水污物有机质输人特征. 随着 污染物质进入湖体, 有机质不断发生矿化, 加上富营养化湖泊藻类生物量大 $\left(\delta^{15} \mathrm{~N}\right.$ 为 $5 \%$ 左右, C/N 为 $6 \sim$ $9^{[19]}$ ), 所有这些都将不断地改变象湖沉积物有机质的 $\delta^{15} \mathrm{~N} 、 \delta^{13} \mathrm{C}$ 及有机 $\mathrm{C} / \mathrm{N}$ 组成, 各个采样点数据比较分 散(图 3). 所以象湖表层沉积物 $\delta^{15} \mathrm{~N} 、 \delta^{13} \mathrm{C}$ 及有机 $\mathrm{C} / \mathrm{N}$ 组成既是湖泊外源污染物有机质的反映, 又是内源 有机质的反映.

三角帆蚌是淡水生态系统中广泛存在的大型底栖动物, 常被用于环境监测 ${ }^{[20]}$. 蚌湖蚌类 $\delta^{15} \mathrm{~N}$ 在 $9.4 \% 0 \sim 10.9 \%$ 之间, 均值为 $9.9 \% 0 \pm 0.8 \%$; 象湖蚌类 $\delta^{15} \mathrm{~N}$ 在 $3.3 \% 0 \sim 5.2 \%$ 之间, 均值为 $4.0 \% 0 \pm 1.0 \%$ (图 $3)$. 蚌湖和象湖蚌类 $\delta^{15} \mathrm{~N}$ 差异较大, 但分别与各自湖泊表层沉积物 $\delta^{15} \mathrm{~N}$ 的相对应, 这是因为蚌类常年栖息 于湖底,滤食湖底的有机碎屑、浮游生物、细菌等, 作为初级消费者其 $\delta^{15} \mathrm{~N}$ 与栖息地范围、类型及沉积物 $\mathrm{N}$ 有显著相关性 ${ }^{[21-22]}$.

\section{3 结论}

蚌湖和象湖 2 个不同类型湖泊无论从 $\mathrm{N}$ 含量还是 $\mathrm{N}$ 同位素组成来看差异都较明显. 根据水体 $\delta^{15} \mathrm{~N}$ 和 沉积有机质 $\delta^{13} \mathrm{C} 、 \delta^{15} \mathrm{~N}$ 及有机 $\mathrm{C} / \mathrm{N}$ 可以大致识别蚌湖和象湖水体无机氮和有机质的来源.

\section{4 参考文献}

[ 1 ] Kling HJ, Mugidde R, Hecky RE. Recent changes in the phytoplankton community of Lake Victoria in response to eutrophication. In: Munawar M, Becky R eds. The great lakes of the world (GLOW) : food-web, health and integrity. Leiden, the Netherlands: Backhuys Publishers, $2001: 47-65$.

[ 2 ] Nyenje PM, Foppen JW, Uhlenbrook S et al. Eutrophication and nutrient release in urban areas of sub-Saharan Africa-A review. Science of the Total Environment, 2010,408:447-455.

[ 3 ] Lv J, Wu HJ, Chen MQ. Effects of nitrogen and phosphoruson phytoplankton composition and biomass in 15 subtropical, urban shallow lakes in Wuhan, China. Limnologica, 2011,41 : 48-56.

[ 4 ] Gu B, Chapman AD, Schelske CL. Factors controlling seasonal variations in stable isotope composition of particulate organic matter in a soft water eutrophic lake. Limnology and Oceanography, 2006,51 : 2837-2848.

[ 5 ] 张振克, 吴瑞金, 王苏民等. 全新世大暖期云南洱海环境演化的湖泊沉积记录. 海洋与湖沼, 2000,31(2):210-214.

[6] Meyers PA. Perseveration of elemental and isotope source identification of sedimentary organic matter. Chemical Geology, $1994,114: 289-302$.

[ 7 ] 国家环境保护总局《水和废水监测分析方法》编委会. 水和废水监测分析方法:第 4 版. 北京: 中国环境科学出版 社, 2002 .

[8] 肖化云,刘丛强. 水样硝酸盐氮同位素分析预处理方法探讨. 岩矿测试,2002,21(2): 105-108.

[9] 赵艳霞,侯 青,徐晓斌. 2005 年中国酸雨时空分布特征. 气候变化研究进展,2006,9(5):242-245.

[10］丁国安,徐晓斌,房秀梅等. 中国酸雨现状及发展趋势. 科学通报,1997,42(2):169-173.

[11] Quirós R. The relationship between nitrate and ammonia concentrations in the Pelagie zone of lakes. Limnetica, 2003,22 $(1 / 2): 7-50$.

[12] Kendall C. Tracing sources and cycling of nitrate in catchments. In: Kendall C, Mcdonnell JJ eds. Isotope tracers in catchment hydrology. Amsterdam: Elsevier, 1998: 519-576.

[13] Chang CCY, McCormick PV, Newman S et al. Isotopic indicators of environmental change in a subtropical wetland. Ecological Indicators, 2009,9 : 825-836. 
[14] Jones RI, King L, Dent MM et al. Nitrogen stable isotope ratios in surface sediments, epilithon and macrophytes from upland lakes with differing nutrient status. Freshwater Biology, 2004,49:382-391.

[15] Kendall C, Elliott EM, Wankel SD. Tracing anthropogenic inputs of nitrogen to ecosystems. In: Michener R, Lajtha K eds. Stable isotopes in ecology and environmental science. Oxford: Blackwell Publishing, 2007:375-449.

[16] Xiao HY, Liu CQ. Identifying organic matter provenance in sediments using isotopic ratios in an urban river. Geochemical Journal, $2010,44: 181-187$.

[17] Sigleo AC, Macko SA. Carbon and nitrogen isotopes in suspended particles and colloids, Chesapeake and San Francisco estuaries, USA. Estuarine, Coastal and Shelf Science, $2002,54: 701-711$.

[18] Dean WE. The carbon cycle and biogeochemical dynamics in lake sediments. Journal of Paleolimnology, 1999,21(4) : 375-393.

[19] Owens NJP, Law CS. Natural variations in ${ }^{15} \mathrm{~N}$ content of riverine and estuarine sediments. Estuarine, Coastal and Shelf Science, $1989,128: 407-416$.

[20] 尤 平,任 辉. 底栖动物及其在水质评价和监测上的应用. 淮北煤炭师范学院学报,2001,22(4):44-48.

[21] Xu J, Zhang M. Primary consumers as bioindicator of nitrogen pollution in lake planktonic and benthic food webs. Ecological Indicators, $2012, \mathbf{1 4}:$ 189-196.

[22] Mckinney RA, Lake JL, Charpenter MA et al. Using mussel istope ratios to assess anthropogenic nitrogen inputs to freshwater ecosystems. Environmental Monitoring and Assessment, 2002,74: 167-192. 